\title{
Diffuse KATP-Associated Hyperinsulinism
}

National Cancer Institute

\section{Source}

National Cancer Institute. Diffuse KATP-Associated Hyperinsulinism. NCI Thesaurus.

Code C131843.

KATP-associated hyperinsulinism affecting all pancreatic beta cells. 